\title{
Determinant Factors Influencing Honey Consumption Trends in Mekelle City, Tigray, Ethiopia
}

\author{
Hailekiros Abraha Aregawi ${ }^{1,2}$ \\ ${ }^{1}$ Department of Marketing Management, Mekelle University, Tigray, Ethiopia \\ ${ }^{2}$ Ethiopian Meat and Dairy Industry Development Institute, Bishoftu, Ethiopia
}

Email address:

johnhaile2008@gmail.com

\section{To cite this article:}

Hailekiros Abraha Aregawi. Determinant Factors Influencing Honey Consumption Trends in Mekelle City, Tigray, Ethiopia. European Business \& Management. Vol. 6, No. 5, 2020, pp. 105-115. doi: 10.11648/j.ebm.20200605.11

Received: February 17, 2020; Accepted: March 2, 2020; Published: September 10, 2020

\begin{abstract}
Beekeeping in Ethiopia contributed to foreign earnings, employment, food, and industrial raw materials. The study aimed to investigate factors influencing the choice of consumption and quantity consumed in Mekelle City, where there was no information on present quantity consumed and factors influencing the choice for honey consumption. Specifically, the study was determined the present quantity consumes and investigates factors influencing the choice for honey consumption in the study area. Kedamay weyane, Hawelti, Adihaki and Hadnet were purposely selected in Mekelle City due to availability of honey market. Clustering and simple random sampling technique was employed in selecting 398 households. Both descriptive and quantitative statistics were used. The result shows that total annual quantity of honey consumption per household were $3 \mathrm{~kg}$ in study area. Binary logistic regression was used in modeling the choice for honey consumption. Binary logistic regression results show that, income, household size, education, availability, quality, price, and policy issues were significant at $5 \%$ $(\mathrm{P}<0.05)$ influencing the honey consumption in the study area. The study concluded that honey was consumed in low level in Mekelle and recommended awareness creation on the benefits of honey, develop mechanism for traceability and promote beekeeping, increase availability of honey, manage and control price of honey through government and other stockholders.
\end{abstract}

Keywords: Honey Consumption, Quality, Price, Availability, Awareness, Policy Issues

\section{Introduction}

Honey is a honeybees' product that stands as one of the natural resources of significant importance socially and economically. It is well known and consumed in various places all over the world [1] However, in recent years, human consumption of honey and honey-products has become popular in different countries [2]. The largest consumers of honey in the world market are the United States with around 153,000 tones, China with around 123,000 tones and Germany that consumes about 90,000 tons/annum AAFRD, (2005) cited by [1].

Ethiopia is known for its large varieties of agro-climatic conditions and biodiversity, which includes good survival of diversified honeybee flora and a large number of honeybee colonies [3]. Because of this, Ethiopia is a leading country in Africa and ninth in the world in honey production. Considering beeswax production, it is the first in Africa and third in the world [4]. Ethiopia has potential natural resources to produce 500,000 tons/annum and currently, honey production is $53,675.36$ tons [5].

Tigray is one of the major honey producer regions in Ethiopia that accounts about $4 \%$ of the total honeybee colonies $(206,040)$ and $15.8 \%$ of the total honey production of national beekeeping potential [5]. However, from the total honey production in Ethiopia, is sold and consumed through formal and informal domestic spot markets. Based on fact that the market for honey in Ethiopia, particularly in Tigray is dominated by the domestic market and hence, the producers and processors should understand consumer behavior trends for successful honey market. Besides, producing honey that meets the quality and quantity demands of consumers and designing appropriate production and marketing policies requires an understanding of the major factors that influence the honey market.

Honey produced in Ethiopia is consumed in raw or processed state in the local markets. However, urban centers remain the hub for many foods and non-food product's 
market in the country. Honey is consumed for different uses such as food, medicinal and ingredient for other products. This in effect necessitates honey producers, processors and suppliers to understand the consumers' need so as to increase their product satisfaction \& development of beekeeping sector in Ethiopia in particular Tigray region. That demands to focus of studying on factors influencing honey consumption in Mekelle city.

Beekeeping is important for the households as a source of food, income generation for both domestic market, export markets, as an employment opportunity, to sustain green environment and other cultural aspects. Around 2,000,000 farm households of the country are involved in beekeeping business using the traditional, transitional and improved beehives. The value chain actors: collectors and retailers participate in honey collection and retailing and many households practiced tej-making [6] particularly it is women's best earning means. Honey production has economic and social importance for households, smallholder farmers, industries and other actors even with the absence of organized information regarding the consumption of honey. In addition, the consumption estimate of honey is based on generalization and it is estimated that about $98 \%$ of honey produced annually consumed locally in Ethiopia and $85 \%$ of this is purchased by brewers of tej [5]. Explicitly, such estimates are likely to be exaggerated and do not provide relevant information that can aid in effective decision making with regard to beekeeping development plans. For this to be effective there is a need for the systematic empirical study to establish consumption estimates for honey.

Most of the previous studies in Ethiopia particularly in Tigray, were done on determinants of adoption of improved box hive [7], market chain analysis of honey production [8], beekeeping adoption strategies to climate change [9], honey market constraints and opportunities, adoption of improved box hive technology [10]. However, none of the above studies have paid attention to specifically quantify the emerging pattern of honey consumption and factors that influence it, regardless of its awareness and realized economic contribution to honey producers, suppliers, dealers and processors in the region and in Mekelle in particular. In recent years, many people in Ethiopia mainly urban centers have been deeply attracted in honey consumption that resulted beekeeping practice popular in various places in the country. Furthermore, there was inadequate information on factors influencing the decision and choice of honey consumption in Mekelle. Therefore, the study has principal importance in analyzing the factors influencing honey consumption and setting baseline information regarding factors influencing honey consumption that assisted honey producers and processors in production and processing planning.

Objectives

1. To determine the current quantity of honey consumed in the study area.

2. To investigate factors affecting households honey consumption.

\section{Material and Methods}

To facilitate conducting the empirical analysis, the results of descriptive and explanatory analyses was used, followed by the inferential analysis. Data was collected from household found in the four sub-cities. About 398 questionnaires were prepared and distributed to the respondents, out of which 385 were completed and retrieved successfully. [11] Stated that a response rate of $50 \%$ is adequate for analysis and reporting; a rate of $60 \%$ is good while a response rate of $70 \%$ and over is excellent. Hence, the presentation, analysis, and interpretation were based on $96 \%$ return rate. This response rate was sufficient that conforms to such prerequisite. The Pearson's Product Moment Correlation Coefficient and regressions were analyzed.

\section{Result and Discussion}

\subsection{Socio-Economic/Demographic Characteristics of Households}

Socio-economic characteristics of households have important social and economic implications on various human aspects including household consumption. Ability of households' decision-making is in most circumstances a result of socio-economic effect.

\subsubsection{Sex and Age of Respondents}

The research found that, sex difference among households does not have influence on household decision making with regard to consumption in the study area. The finding from figure 1 show that the household heads were in the category of economically active and working age group when compared to the average proportion reported for the, which was $52.2 \%$ (22-45 years) [5].

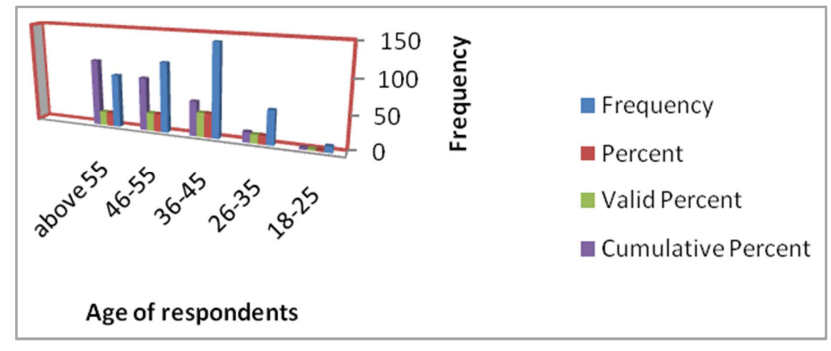

Figure 1. Respondents' Agee.

The results revealed that, in the study area the overall proportion of male and female headed households constitutes $260(67.5 \%)$ and $125(32.5 \%)$ respectively. In general, the result shows that the proportion of male-headed households was higher than female-headed households. It is an ideal for household decision making with regard to consumption patterns. However, this research found that, sex difference among households does not have influence on household decision making with regard to consumption in the study area. 
Table 1. Respondents' sex.

\begin{tabular}{lllll}
\hline Sex & Frequency & Percent & Valid percent & Cumulative percent \\
\hline Male & 260 & 67.5 & 67.5 & 67.5 \\
Female & 125 & 32.5 & 32.5 & 100.0 \\
Total & 385 & 100.0 & 100.0 & \\
\hline
\end{tabular}

\subsubsection{Education Level and Occupation of Respondents}

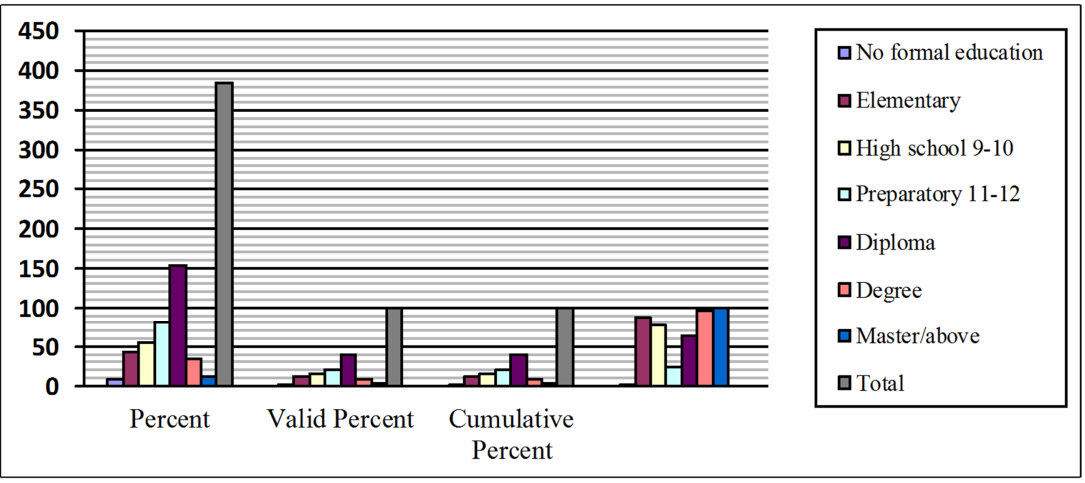

Figure 2. Respondents Educational level.

Figure 2 demonstrated that $40 \%$ of the respondents hold diploma, $20.8 \%$ preparatory, $14.3 \%$ were high school completed, $10.9 \%$ elementary, $8.8 \%$ were degree, $3.1 \%$ hold master's and above, and the remaining $2.1 \%$ were non formal education. From this result, it can be noted that the majority of respondents were hold diploma completed. Table 2 indicated that the majority of respondents were business owners. Reasonably, this is a good indication of household labor supply, which can influence the increased household income and consumption.

Table 2. Occupational status of respondents.

\begin{tabular}{lllll}
\hline Occupation & Frequency & Percent & Valid Percent \\
\hline Public employee & 130 & 33.8 & 33.8 & Cumulative Percent \\
Private employee & 73 & 19.0 & 19.0 & 33.8 \\
Business owner & 150 & 39.0 & 39.0 & 52.7 \\
Student & 6 & 1.6 & 1.6 & 91.7 \\
Unemployed & 26 & 6.8 & 6.8 & 93.2 \\
Total & 385 & 100.0 & 100.0 & 100.0 \\
\hline
\end{tabular}

Table 2 indicated that the majority of respondents were business owners. Reasonably, this is a good indication of household labor supply, which can influence the increased household income and consumption.

\subsubsection{Respondents' Monthly Income and Household Size}

Household real income was important characteristics to realize honey consumption situation. Table 3 indicated that the majority of respondents' monthly income was in between 2001- 3000 birr. Logically, this may contribute the increased household income for decision making with regard to honey consumption. The finding justified how household income determined choice and decision of honey consumption trend in the study area. The result implied that low income household purchased little honey for their consumption as compared to households with medium and high-income demand for more honey. The finding was consistent with [12] contended that poor people were least consumers, while medium to rich respondents were frequent consumers.

Table 3. Respondents' Monthly income.

\begin{tabular}{lllll}
\hline Monthly income & Frequency & Percent & Valid Percent \\
\hline Less than 1000 & 13 & 3.4 & 3.4 & Cumulative Percent \\
$1001-2000$ & 33 & 8.6 & 4.6 & 47.5 \\
$2001-3000$ & 183 & 47.5 & 31.2 & 34.5 \\
$3001-4000$ & 120 & 31.2 & 9.4 & 90.6 \\
above 4000 & 36 & 9.4 & 100.0 \\
Total & 385 & 100.0 & 100.0 \\
\hline
\end{tabular}

The study implied that in majority of household's family members of the study area were five that the research result was similar to an Ethiopian household budget survey in 2011 that indicated that average household size of Ethiopian mainland was five people [5]. The number of household persons in the study area was ideal and can have influence on 
the quantity and consumption pattern of honey and other human consumption bundles at time.

Table 4. Household size.

\begin{tabular}{lllll}
\hline Household size & Frequency & Percent & Valid Percent & Cumulative Percent \\
\hline 1 & 10 & 2.6 & 2.6 & 2.6 \\
2 & 25 & 6.5 & 6.5 & 9.1 \\
3 & 50 & 13.0 & 13.0 & 22.1 \\
4 & 110 & 28.5 & 28.6 & 50.6 \\
5 & 175 & 45.6 & 45.5 & 96.1 \\
6 and above & 15 & 3.9 & 3.9 & 100.0 \\
Total & 385 & 100.0 & 100.0 & \\
\hline
\end{tabular}

The study implied that in majority of household's family members of the study area were five that the research result was similar to an Ethiopian household budget survey in 2011 that indicated that average household size of Ethiopian mainland was five people [5]. The number of household persons in the study area was ideal and can have influence on the quantity and consumption pattern of honey and other human consumption bundles at time.

\subsection{Reliability Analysis}

Before analyzing the data collected, the study the scale's reliability test for the main items of the questionnaire was conducted. The reliability of the scale containing 14 questions to determine the factors influencing on honey consumption and tested using Cronbach's alpha that ranges from 0 to 1. According to Hair et al. (2006), [12], a coefficient alpha greater than or equal to 0.7 is considered acceptable and a good indication of construct reliability. The reliability coefficient for all items was above 0.7 and the overall reliability test for the items or questions was 0.864 (86.4\%). This implied acceptable and a good indication of construct reliability for the main items of the questionnaire (Table 5).

Table 5. Reliability Analysis.

\begin{tabular}{lll}
\hline Variables & $\begin{array}{l}\text { Number of } \\
\text { items }\end{array}$ & $\begin{array}{l}\text { Cronbach's } \\
\text { Alpha }\end{array}$ \\
\hline Availability & 1 & 0.822 \\
Quality issues & 1 & 0.832 \\
Price & 1 & 0.847 \\
Market information & 1 & 0.821 \\
Distance to market & 1 & 0.813 \\
Policy issues & 1 & \\
Total & 6 & 0.848 \\
Honey consumption & & \\
Honey consume or not consume & 8 & 0.845 \\
Overall reliability & 14 & 0.864 \\
\hline
\end{tabular}

\subsection{Model Test of Multi Collinearity}

Multi Collinearity problem is the existence of a "perfect," or exact, linear relationship among some or all-independent and explanatory variables of a regression model [13]. MultiCollinearity diagnostics test was done to check the presence of high Collinearity among and between the dependent and each independent variable. In order to test the existence of multi Collinearity problem, the Pearson correlation matrix was utilized. Chatterjee, Hadi, and Price (2000) set the general rule for multi Collinearity to be a severe problem, if the mean value of VIF exceeds 10 and falls below one (i.e., $1<$ mean VIF $<10$ ). VIF result in table 6 shows that, there is no perfect Collinearity among and between explanatory variables because the mean value of VIF is 2.678. MultiCollinearity can be a problem if and only if mean value of VIF value exceeds 10 .

Table 6. Test of multi collinearity.

\begin{tabular}{lll}
\hline \multirow{2}{*}{ Variables } & \multicolumn{2}{l}{ Collinearity Statistics } \\
\cline { 2 - 3 } & VIF & 1/VIF \\
\hline Sex & 4.426 & 0.225937 \\
Age & 5.399 & 0.185294 \\
Household size & 1.289 & 0.775795 \\
Educational & 3.072 & 0.325520 \\
Income & 2.540 & 0.393700 \\
Availability & 1.599 & 0.625390 \\
Quality issues & 1.822 & 0.548847 \\
Distance to market & 4.736 & 0.211148 \\
Market information & 1.960 & 0.510204 \\
Price & 1.273 & 0.785545 \\
Policy issues & 1.349 & 0.741289 \\
Mean VIF & 2.678 & \\
\hline
\end{tabular}

\subsection{Proportion of Honey Consumers}

Purchasing proportion of households for honey consumption in the study area was investigated. The finding displayed in Figure 3, agreed with [12] that the choice for purchasing place may be contributed by education level, where market places are preferred by people with low level of education while supermarkets preferred by people with high level of education.

The price at the local markets in relation to other sources were relatively low prices $200-350 \mathrm{birr} / \mathrm{kg}$ as compared to supermarkets $250-450 \mathrm{birr} / \mathrm{kg}$ for all types of honey in color. Besides the price the types of honey in the study area were found white 300-450 birr $/ \mathrm{kg}$, yellow 250-300 birr $/ \mathrm{kg}$, and amber 150-250 birr/kg and white honey was very expensive. Furthermore, in the study area price of honey was low in the harvest seasons (October to January), on the other hand, price of honey was high in seasons like April and March. On the other hand, the study revealed that in most cases hawkers in the streets sells honey at low prices than other market places through bargaining but of unreliable sources, and with this result to many people unlike to purchase honey from hawkers in the study area. However, the respondents pointed that the prices of honey in local market tend to varied significantly depending on the availability or seasons. 


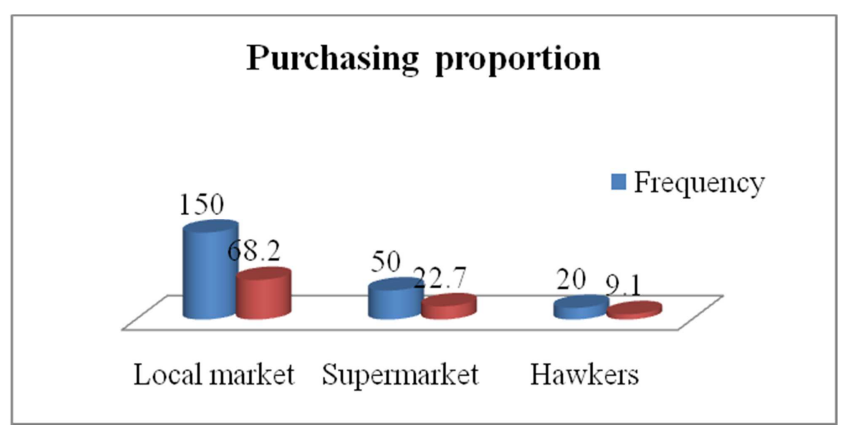

Figure 3. Purchasing Proportion of households on honey consumption.

During harvesting seasons, honey is more available and the prices tend to be low, however, the interview with one of honey dealer in the city market revealed that the price is highly influenced by the number of large buyers who export honey to Sudan and honey export from Ethiopia to other countries was mostly from Tigray. The results indicated that market places remain as the hub for honey product where some of the households obtain their honey for consumption specially from local market regardless of their income in the study area. These results are similar to the results obtained by [12] who found that households regardless of their income categories commonly uses local market and retail groceries for food purchases while supermarkets are often used by wealthier households in urban areas of Zambia.

\subsection{Quantity of Honey Consumed}

Figure 4 displayed frequency of purchasing honey for different household was 1-2 times/year indicating purchasing behavior for honey was low in the study area, which in turn results to low consumption frequency of honey among the households. Furthermore, due to low level of awareness on the benefits of honey, regular increase in price, low quality, market information and other households purchase frequency factors were low. However, it is worth to note that, the consumption of honey may not be viewed along the category of general food habits, and being associated with people's welfare rather it remains the matter of preferences and perceived values of honey among consumers.

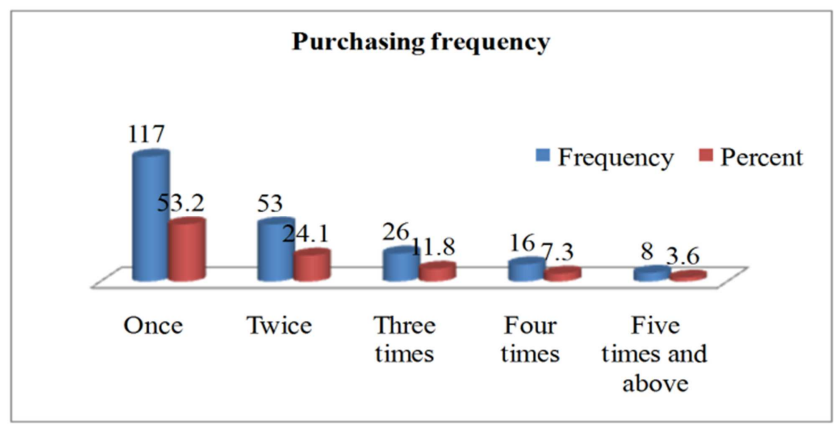

Figure 4. Proportion of households on purchasing frequency of honey.

The study result agreed to the finding of [12] that consumption of honey may not be viewed along the category of general food habits, and being associated with people's welfare. In addition, the results imply that the tendency of honey purchase frequency for consumption among honey consumers in the households based on their income level in the study area. High proportion of households purchasing honey once in a year implies that the consumption habit for honey is low in Mekelle, and this may be contributed by low consumers' exposure to honey uses. Based on the finding of the study socio economic characteristics of households, marketing factors, and policy related issues, as health and economic benefit of honey the consumption level of households in Mekelle was low (Table 7).

The study revealed five consumption patterns of honey among household in the study area, which include use of honey as food, healing medication, substitute for sugar in tea, as tej and substitute for margarine in bread. Figure 5 remarked, the proportion of households' utilization pattern, honey for healing medication, and this may be attributed by healing property of honey as reported in [1], "honey has antibacterial and antimicrobial qualities which are resistant to some antibiotics". Besides to stresses that honey consumption in regular manner has been shown to reduce blood sugar in the body which in turn results to increase metabolism.

Table 7. Distribution of quantity of honey in $\mathrm{kg}$ purchased and consumed/year.

\begin{tabular}{lllll}
\hline Quantity in kg & Frequency & Percent & Valid Percent & Cumulative Percent \\
\hline $1 \mathrm{~kg}$ & 40 & 10.4 & 18.2 & 18.2 \\
$2 \mathrm{~kg}$ & 60 & 15.6 & 27.3 & 45.5 \\
$3 \mathrm{~kg}$ & 105 & 27.3 & 47.7 & 93.2 \\
$4 \mathrm{~kg}$ & 9 & 2.3 & 4.1 & 97.3 \\
$5 \mathrm{~kg}$ and above & 6 & 1.6 & 2.7 & 100.0 \\
Total & 220 & 57.1 & 100.0 & \\
\hline
\end{tabular}

The result from figure 5 was similar to the findings by [14] who reported that high proportion of households' uses honey for healing or medication. Other studies also found that, medication, food and sweetening were isolated as the major motivations for honey consumption [15]. Moreover, of the households use honey as food substance and this contributed by sweet taste and nutritional value of honey. The fact that honey is a natural product and has therapeutic as well as medicinal properties, which may attract many people to engage in honey consumption, particular in the current context of health consciousness among people [12]. Similarly, some of the respondents from the households reported their use of honey for treating coughs as well as burnt body surface and wound dressing. However, still honey was consumed as it was believed in culture but not as food substance contributed nutritional value and that would have 
also an effect on the diet balance of the households in the study area.

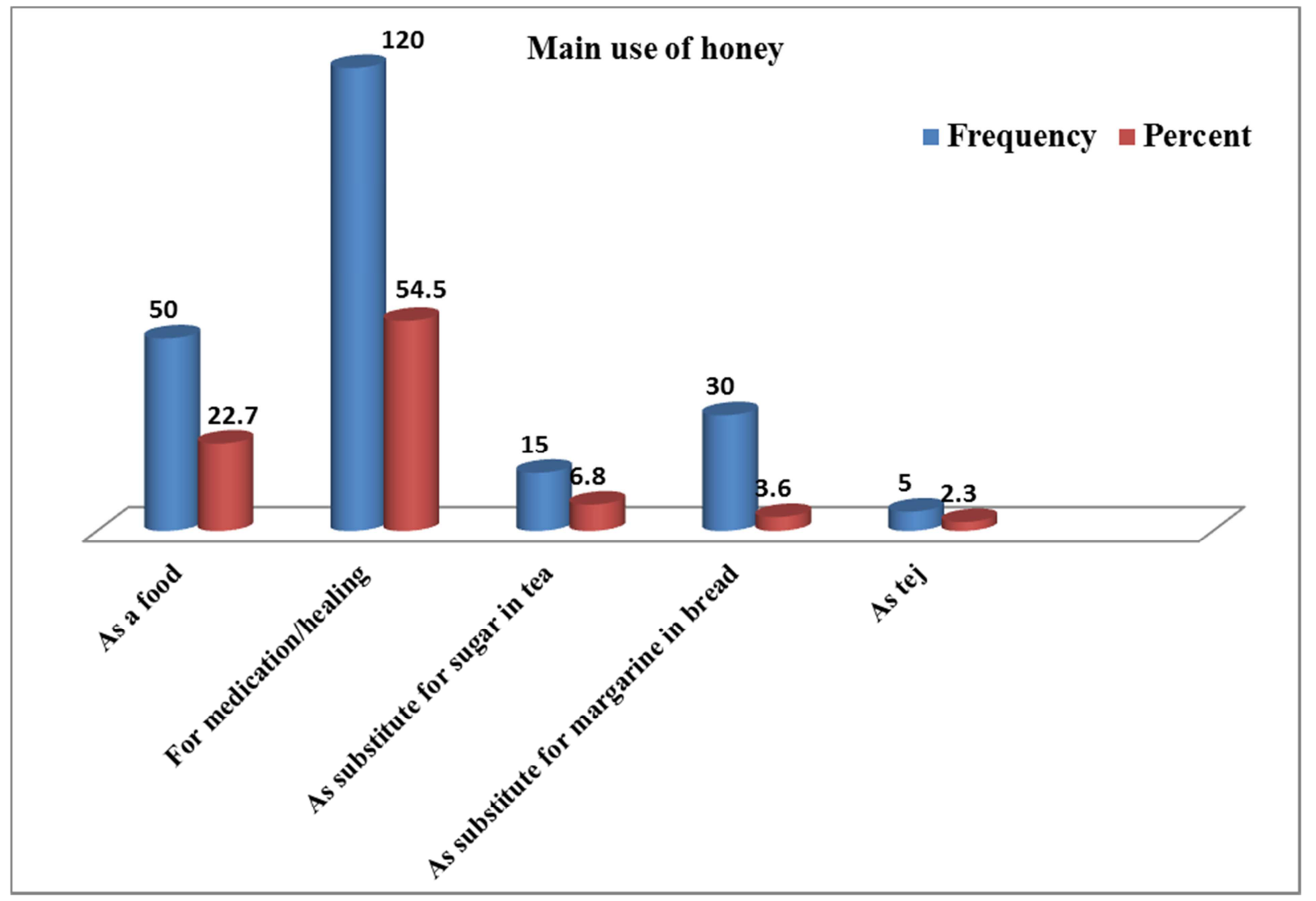

Figure 5. Proportion of households on consumption pattern of honey.

\subsection{Factors Influencing Households' Choice and Decision for Honey Consumption}

The study revealed factors influencing the choice for honey consumption among households in Mekelle as frequent availability of honey, affordable purchasing price, market distance to home, adequate market information, freeness of adulteration (cholesterol \& dangerous sugar content) and awareness due to current government initiatives on beekeeping benefits of honey. Factors influencing honey consumption choice were estimated to determine how household behave in making decision given various products available in the market for consumption. So as to determine the significance of factors that influences households' choice for honey consumption amongst the available options in the study areas, binary logit model was used. This was done in order to test which states that 'household socio-economic characteristics, product characteristics, market characteristics, and other factors equally influence honey consumption choice among households. The model accommodated the binary value, which was a reflective to the consumption situation available in the study areas to represent the dichotomous dependent variable. The logistic binary equation that was developed for this study accommodated the dependent variable that was dichotomized as household consume or not consume honey.

The explanatory variables that were accommodated in the binary logistic regression equation included the variables, which were revealed by the respondents and selected social economic variables to test their effect and to suit the study goal. The variables revealed by households were frequent availability of honey in the urban center $(\mathrm{AVH})$, price per $\mathrm{kg}$ of honey offered at the market $(\mathrm{PH})$, quality of honey or freeness of dangerous sugar content or adulteration $(\mathrm{QH})$, distance to home (DH), market information (MIN), and awareness due to current government initiatives on beekeeping and benefit of honey.

On the other hand, socio-economic variables which were considered to test whether it influence the consumption of honey includes; sex of the household head (SEX), education level of the household head (ELHH), age of household head (AHH), household income (HOINC) and household size (HHS). The variables used in the binary logistic regration model are summarized in Table 8 below. The study conjectured that, household choice for honey consumption is influenced by socioeconomic factors; however, the study revealed that embedded characteristics of honey product and government policy implementation were among factors influencing the consumption of honey as respondents pointed out and which used in this study as the explanatory variables. The basis for the assumption was theoretical considerations found in the literature in which the independent variables may have influence on dependent variable in either positive or negative direction $[12,1,15]$. 
Table 8. Variables used in the logistic regration model.

\begin{tabular}{llll}
\hline Dependent variable & Description & Type & Values \\
\hline HHC & Household honey consumption & Dummy & $0=$ Not consume 1=Consume \\
Independent variables & & & $0=$ Female, $1=$ male \\
SEX & Sex of household head & Dummy & Number of years \\
AHH & Age of household head & Categorical & Number of years \\
ELHH & Education level of household & Categorical & Number in Birr \\
HOINC & Household income & Categorical & Number of households \\
HHS & Household size & Continuous & $0=$ No, $1=$ Yes \\
AVH & Availability of honey & Dummy & $0=$ No, $1=$ Yes \\
QH & Quality of honey & Dummy & $0=$ No, $1=$ Yes \\
PH & Price of honey & Dummy & $0=$ No, $1=$ Yes \\
MIN & Market information & Dummy & $0=$ No, $1=$ Yes \\
DH & Distance to home & Dummy & $0=$ No, $1=$ Yes \\
AWG & Awareness due to government & Dummy & \\
\hline
\end{tabular}

\subsection{Correlation Analysis}

Table 9 below described the result of Pearson correlation on the relationship between factors influence and honey consumption, that, except price and distance to market all independent variables (factors influence) are positively and significantly correlated with the dependent variable (honey consumption) at $99 \%$ confidence level and at $1 \%$ significant level $(p<0.01)$. While price and distance to market have negative and significant correlation with honey consumption. Household size and honey consumption was statistically significant at $99 \%$ confidence level. This implies that at a $1 \%$ level of significance it was discovered that quality, income level, educational level and frequent availability of honey plays a significant role in determining honey consumption in the study area. The normal correlation is between policy issue and honey consumption $(\mathrm{r}=0.668)$, market information and honey consumption $(\mathrm{r}=0.480)$. Whereas; the weakest correlation is between age and honey consumption $(\mathrm{r}=0.297)$, and sex and honey consumption $(\mathrm{r}=0.283)$.

Furthermore, based on the Pearson correlation test in Table 9 , quality issue is positive and significantly correlated with honey consumption. The correlation between quality and honey consumption was highly correlated as factors influencing honey consumption $(\mathrm{r}=0.836)$. That indicated quality issues like adulteration determined honey consumption to guarantee households honey consuming behavior. moreover, income level was positive and significantly correlated with honey consumption. Income and honey consumption were the highly correlated $(\mathrm{r}=0.811)$. That implied with increase income level, the households honey consumption would get improved. In addition, income provided households to invest and raise their honey consumption.

Education level was another factor influencing honey consumption, implying as educational level increase, the households honey consumption would be increase since education creates awareness and wealth that influences decision making regarding honey consumption and other consumption options. Besides, educational improvement could lead to awareness of honey consumption. The other factor that was included in factors influencing honey consumption was honey availability. It was significant relationship with honey consumption $(\mathrm{r}=0.798)$ and implied that, the more frequent availability of honey the better honey consumption of households would be. Table 9, Market information was significant with household's honey consumption indicating household's market information increased honey consumption. Policy issue was another element of factors influence household honey consumption that is taken in to consideration to improve consumer-buying behavior.

Policy issue was significant relationship with honey consumption implying as awareness due to current government initiatives on beekeeping and honey consumption benefit increase, consumers would get improve their honey consumption behavior. Factors negatively influencing honey consumption was regular increase in price that was negatively significant relationship with honey consumption $(\mathrm{r}=-0.351)$. As price increased regularly the households honey consumption probability declined. As Table 9 remarked, distance to home has a negatively significant relationship with consumer buying behavior ( $\mathrm{r}=-$ 0.441 ), indicating as market distance to home increased the probability of household's honey purchasing and consumption would be decreased.

Age has a weak correlation with honey consumption $(\mathrm{r}=0.283)$ implying that it was not much significance influence on household's honey consumption decision. Sex of household has a weakly significant relationship with honey consumption $(\mathrm{r}=0.297)$. This indicates that, sex has a weak correlation with honey consumption. Implying that sex did not have significance influence regard to household's honey consumption decision. In general, the correlation results in Table 8 revealed that majority of the relationship between independent and dependent variables were directly related. That implied if factors influencing the honey consumption were properly managed, the buying and consuming behavior of households would get improved. 
Table 9. Correlation between independent and dependent variables.

\begin{tabular}{|c|c|c|}
\hline Independent Variables & & Honey Consumption \\
\hline \multirow{4}{*}{ Sex } & Pearson Correlation & $.297^{* *}$ \\
\hline & Sig. (2-tailed) & .000 \\
\hline & $\mathrm{N}$ & 385 \\
\hline & Pearson Correlation & $.283^{* *}$ \\
\hline \multirow[t]{3}{*}{ Age } & Sig. (2-tailed) & .000 \\
\hline & $\mathrm{N}$ & 385 \\
\hline & Pearson Correlation & $.689^{* *}$ \\
\hline \multirow[t]{3}{*}{ Household size } & Sig. (2-tailed) & .000 \\
\hline & $\mathrm{N}$ & 385 \\
\hline & Pearson Correlation & $.802^{* *}$ \\
\hline \multirow[t]{3}{*}{ Educational level } & Sig. (2-tailed) & .000 \\
\hline & $\mathrm{N}$ & 385 \\
\hline & Pearson Correlation & $.811^{* *}$ \\
\hline \multirow{3}{*}{ Monthly income } & Sig. (2-tailed) & .000 \\
\hline & $\mathrm{N}$ & 385 \\
\hline & Pearson Correlation & $.798^{* *}$ \\
\hline \multirow[t]{3}{*}{ Availability } & Sig. (2-tailed) & .000 \\
\hline & $\mathrm{N}$ & 385 \\
\hline & Pearson Correlation & $.836^{* *}$ \\
\hline \multirow[t]{3}{*}{ Quality issues } & Sig. (2-tailed) & .000 \\
\hline & $\mathrm{N}$ & 385 \\
\hline & Pearson Correlation & $-.441^{* *}$ \\
\hline \multirow[t]{3}{*}{ Distance to market } & Sig. (2-tailed) & .000 \\
\hline & $\mathrm{N}$ & 385 \\
\hline & Pearson Correlation & $.480^{* *}$ \\
\hline \multirow[t]{3}{*}{ Market information } & Sig. (2-tailed) & .000 \\
\hline & $\mathrm{N}$ & 385 \\
\hline & Pearson Correlation & $-.351^{* *}$ \\
\hline \multirow{3}{*}{ Price } & Sig. (2-tailed) & .000 \\
\hline & $\mathrm{N}$ & 385 \\
\hline & Pearson Correlation & $.668^{* *}$ \\
\hline \multirow[t]{2}{*}{ Policy issues } & Sig. (2-tailed) & .000 \\
\hline & $\mathrm{N}$ & 385 \\
\hline
\end{tabular}

**Correlation is significant at the 0.01 level (2- tailed).

\subsection{Binary Logit Regration Model Estimation}

The binary logit Regration model was used to determine the household choices, by examine effects of explanatory variables on the likelihood of choosing honey from a number of alternative products that are available in the study areas. Table 9 summarizes the socio-economic factors hypothesized to influence household choice for honey and the factors revealed in the households.

Table 10. Model Summary.

\begin{tabular}{llll}
\hline Model & $\mathbf{- 2}$ Log likelihood & Cox \& Snell $\mathbf{R}^{2}$ & Nagelkerke $\mathbf{R}^{\mathbf{2}}$ \\
\hline 1 & 8.628 & .589 & .882 \\
\hline
\end{tabular}

As Table 10 displayed, the specified binary model fits well the data as measured by Pseudo $-\mathrm{R}^{2}$ (Cox and Snell $=0.589$ and Nagelkerke $=0.882$ ). The high values of Pseudo $-\mathrm{R}^{2}$ which are $58.9 \%$, and $88.1 \%$ for Cox and Snell and Nagelkerke respectively, suggested a good predictive ability of the model and implying that the explanatory variables included in the model explain well the variation in the dependent variable. According to Louviere et al., (2000) Pseudo- $\mathrm{R}^{2}$ sometimes though rarely, reaches values as high as those of $\mathrm{R}^{2}$ in linear regression; therefore, the presented Pseudo $-\mathrm{R}^{2}$ are still considered having a good fit.
Table 11. Model fitting information.

\begin{tabular}{llll}
\hline Model & Chi-square & df & Sig. \\
\hline 1 & 83.211 & 10 & .001 \\
\hline
\end{tabular}

Furthermore, the Chi-square statistic showed the model was highly significant at $5 \% \quad(\mathrm{P}<0.05)$, indicating that coefficients for all variables included in the model were jointly different from zero. All these confirm that there was a relationship between the dependent variable and explanatory variables included in the model. Moreover, the important thing in binary logistic regration model for any choice analyst was to describe the overall test of a relationship, in this case a relationship between the dependent and independent variables. The existence of a relationship between the dependent and independent variables is based on the statistical significance of the final model chi-square termed model fitting information (Table 11). In this analysis, the model reveals that the probability of the model chi-square (83.211) was 0.001 , less than the level of significance of 0.05 $(\mathrm{P}<0.05)$. Table 8 indicated that, some predictor variables influence honey consumption choice significantly. Of the 11 independent variables used in the model, seven factors were statistically significant at 5\% significance level. 
The results indicate that the probability of the choice for honey consumption is significantly and positively influenced by the income level, education level, household size, availability, quality, and awareness of the households on honey consumption. On the other hand, the probability of the choice for honey consumption is significantly and negatively influenced by the price.

The positive coefficients for these variables imply that increase in any units might results to increase in consumption of honey among households. On the other hand, the negative coefficients for these variables imply that increase in any units might results to decrease in honey consumption among households. The binary logistic regration model coefficients give the change in the log odds of the outcome for a one-unit increase in the predictor variable. In this regard, according to Table 12 shows that for every one-unit change in income, education, household size, availability, quality, and awareness due to government, the log odds of honey consumers and nonconsumer's increases by $0.666,4.079,3.597,2.171,1.832$ and 1.959 unit respectively. On the other hand, for every one-unit change in price; the log odds of honey consumer's and nonconsumers decrease by 2.253 unit.

Table 12. Estimated results of the binary logistic regression on honey consumption.

\begin{tabular}{|c|c|c|c|c|c|c|}
\hline & B & S. E. & Wald & Df & Sig. & $\operatorname{Exp}(B)$ \\
\hline Sex & -.599 & 1.303 & .211 & 1 & .646 & .549 \\
\hline Age & 3.857 & 1.313 & 8.634 & 1 & .603 & 7.332 \\
\hline Household size & 3.597 & .916 & 15.402 & 1 & .000 & .027 \\
\hline Education level & 4.079 & .774 & 27.798 & 1 & .000 & .017 \\
\hline Income level & .666 & .300 & 4.930 & 1 & .026 & 1.947 \\
\hline Availability & 2.171 & .583 & 13.853 & 1 & .000 & 8.764 \\
\hline Quality issues & 1.832 & .719 & 6.498 & 1 & .011 & 6.248 \\
\hline Market information & -.194 & .687 & .079 & 1 & .778 & .824 \\
\hline Price & -2.253 & .547 & 16.956 & 1 & .000 & .105 \\
\hline Policy issues & 1.959 & .704 & 7.749 & 1 & .005 & 7.094 \\
\hline Constant & 12.826 & 4.651 & 7.606 & 1 & .006 & 37.084 \\
\hline
\end{tabular}

The standard beta $(\beta)$ coefficient described the unique contribution of each variable to the model. It helped to see the direction and strength of the relationship between independent and dependent variables. If the sign of beta $(\beta)$ coefficient for the independent variable is positive, there is a positive relationship between independent and dependent variables and if the sign of beta $(\beta)$ coefficient for the independent variable is negative, there is a negative relationship between independent and dependent variables. A high beta $(\beta)$ value and a small $p$-value $(<0.05)$ indicate the predictor variable has a significant statistical contribution to the model. Whereas a small beta $(\beta)$ value and a high $p$-value $(>0.05)$ has a little or no statically significant contribution to the model. Table 12, showed that the regression coefficient $(\beta)$ of sex, age, education level, income level, household size, availability, quality, price, market information, distance to market and policy issues. Based on the results of regression coefficient, the study noted that from the factors influencing honey consumption education level, income level, household size, availability, quality, price, and policy issues have statistically significant to influence honey consumption

Other studies also concluded that, low quality, lack of marketing services, the consumers' poor knowledge of honey and so forth were major problems facing the honey consumers in Saudi Arabia [15]. On the other hand, the study noted that from the factors influencing honey consumption sex, age, market information, and distance to market have not statistically significance to influence honey consumption. The result was in line with [14] who reported that statistically insignificant influence of sex, age, market information and distance to market on household honey consumption in Tanzania. Variables like, income level, availability, quality, education level, and policy issue were positively significant influence on household's honey consumption. However, price negatively significant influencing households honey consumption. As Table 12, illustrated income level positively significant influence on honey consumption with a beta value $(\beta=0.666)$ at $95 \%$ confidence level $(p<0.05)$, implying with increase in income level the probability of honey consumption increased by 0.666 unit. Education level has a positively significant influence on honey consumption with a beta value $(\beta=4.079)$ at $95 \%$ confidence level $(p<0.05)$. Table 10 , implied as education level increased the probability of honey consumption increased by 4.079 unit. The result was similar to the findings by [15] who reported that household education level $(\mathrm{P}<0.05)$ positively significance influence on honey consumption in Saudi Arabia.

Household size has positively significant influence on honey consumption with a beta value $(\beta=3.597)$ at $95 \%$ confidence level $(\mathrm{p}<0.05)$ implying increase in household member increases the probability of honey consumption by 3.597 unit (Table 12). Availability has a positively significant influence on honey consumption with a beta value $(\beta=2.171)$ at $95 \%$ confidence level $(\mathrm{p}<0.05)$. This implied as frequent availability honey increase the probability of honey consumption increased by 2.171 unit. Quality has a positively significant influence on honey consumption with a beta value $(\beta=1.832)$ at 95 percent confidence level $(p<0.05)$ This implies as quality issues like freeness of adulteration increase the probability of honey consumption increases by 1.832 unit. The result was similar to the findings by Raymond (2017) who reported that positive and significance influenced free of adulteration $(\mathrm{P}<0.05)$ households on the honey consumption.

Price has a negative and significant influence on honey 
consumption with a beta value $(\beta=-2.253 .808)$ at $95 \%$ confidence level $(p<0.05)$ implying increase price regularly the probability of honey consumption decreases by 2.253 unit In addition, the price of white honey reached ETB 120$130 / \mathrm{kg}$, price for yellow honey was around ETB $60-90 / \mathrm{kg}$, the price for amber honey ranged ETB $30-50 / \mathrm{kg}$ for crude unprocessed honey and 40-60 ETB/ $\mathrm{kg}$ was in the Tigray area [5]. However, the study found that, the price of white honey reached ETB 350-450/kg, price for yellow honey ETB 200 $300 / \mathrm{kg}$, and the price for amber honey ranged ETB 150$250 / \mathrm{kg}$ was in the study area. This shows that, regular increase in price of honey have critical issues that influence honey consumption. In general, the binary logit regression results clearly illustrated that the majority of independent variables have a positive and significant influence on the dependent variable (honey consumption).

Moreover, the relative influence of the independent variables on the dependent variable, income level, availability, price, and quality issue have the higher influence on household's honey consumption. Policy issue has a positively significant influence on honey consumption with a beta value $(\beta=1.959)$ at 95 percent confidence level $(p<0.05)$. This implies as policy issue due to government in awareness creation on benefit of honey and initiatives on beekeeping increase the probability of honey consumption increases by 1.959 unit (Table 12).

To assess quantitative effects of the independent variables, marginal effects were calculated. The marginal effect of binary logistic regression to show the individual effects of explanatory variables on the dependent variables in economic science. Marginal effect has its own great contribution since it shows the results due to change of one variable as a result of change on its corresponding variables. The household size has effect on honey consumption and statically significance at $5 \%$ level of significance. The positive sign of the coefficient of this variable assures that a greater number of persons in household may be consuming honey. Thus, as number of persons in household increased by one person, the probability of being consuming honey will be increased by $8.71 \%$ of the marginal effect, holding other variables constant.

Table 13. Binary logistic regression with marginal effects.

\begin{tabular}{|c|c|c|c|c|c|c|c|}
\hline Honey consumption & $\mathrm{dy} / \mathrm{dx}$ & Std. err & $\mathbf{Z}$ & $\mathbf{p}>|\mathbf{z}|$ & {$[95 \%$ C. I } & & \\
\hline Sex & -.0145128 & .02887 & -0.50 & 0.615 & -.071092 & .042067 & 1.58701 \\
\hline Age & .0934349 & .07299 & 1.28 & 0.200 & -.049623 & .23649 & 4.36104 \\
\hline Household size & .0871271 & .06265 & -1.39 & $0.046 * *$ & -.209916 & .035662 & 3.97403 \\
\hline Educational level & .0988105 & .05566 & -1.78 & $0.016^{* *}$ & -.207897 & .010276 & 3.87013 \\
\hline Income level & .0161375 & .00996 & 1.62 & $0.005 * *$ & -.003375 & .03565 & 2.69351 \\
\hline Availability & .0480065 & .03091 & 1.55 & $0.020 * *$ & -.012573 & .108586 & .376623 \\
\hline Quality issues & .0443855 & .02963 & 1.50 & $0.034 * *$ & -.01369 & .102461 & 1.23377 \\
\hline Distance to market & -.0047904 & .01715 & -0.28 & 0.780 & -.038403 & .028822 & .389612 \\
\hline Price & -.0322052 & .02172 & -1.48 & $0.038 * *$ & -.074738 & .010328 & .828571 \\
\hline Policy issue & .0678119 & .05453 & 1.24 & $0.014 * *$ & -.039057 & .174681 & .625974 \\
\hline
\end{tabular}

$(* *) \mathrm{dy} / \mathrm{dx}$ is for discrete change of dummy variable from 0 to 1 .

\section{(i). Education and Income level}

Education level has effect on honey consumption and statically significance at $5 \%$ level of significance. The positive sign of the coefficient of this variable assures that more educated persons in household motivated honey consumption understanding value of honey ingredient. Thus, as educational level in household increased by one year, the probability of being consuming honey will be increased by $9.88 \%$ of the marginal effect, holding other variables constant. The income level has effect on honey consumption and statically significance at $5 \%$ level of significance. The positive sign of the coefficient of this variable assures that more income level persons in household may be consuming honey. Thus, as income level in household increased by one birr, the probability of being consuming honey will be increased by $1.61 \%$ of the marginal effect, holding other variables constant. The finding showed that educational \& income level were significant factors for honey consumption.

(ii). Honey Availability, Quality, Price \& Policy Issues

The availability has effect on honey consumption and statically significance at $5 \%$ level of significance. As availability increased by one unit, the probability of being consuming honey will be increased by $4.80 \%$ of the marginal effect, holding other variables constant. Quality has effect on honey consumption and statically significance at 5\% level of significance. The probability of honey consumption means that other things remain constant if the quality of honey increases honey consumption also increases. The positive sign of the coefficient of this variable assures that more quality of honey ensured households for consuming honey. Thus, as quality of honey increased by one unit, the probability of being consuming honey will be increased by $4.43 \%$ of the marginal effect, holding other variables constant.

The price has effect on honey consumption and statically significance at $5 \%$ level of significance. The negative sign of the coefficient of this variable assures that regular increase in price of honey affected households in consuming honey. Thus, as price of honey increased by one birr, the probability of being consuming honey will be decreased by $3.22 \%$ of the marginal effect, holding other variables constant. The finding showed that qua price was one main factor for honey consumption. The policy issue has effect on honey consumption and statically significance at 5\% level of significance. The probability of honey consumption means that other things remain constant if the policy issue like awareness creation by the government on honey increases honey 
consumption. The positive sign of the coefficient of this variable assures that more awareness creation on honey in the study area may be households make consuming honey. Thus, as awareness creation of honey increased by one unit, the probability of being consuming honey will be increased by $6.78 \%$ of the marginal effect, holding other variables constant. The finding showed that honey availability, policy, price and quality issues were main factor for honey consumption.

\section{Conclusion and Recommendation}

Based on the study there was no clear honey consumption record trend and pattern practices in Mekelle to help clear area of intervention for health, investment and marketing chain by the concerned government body assigned to facilitate or support honey industry. This has an implication on investment and market chain engagement in the sub sector. The overall result revealed that the main consumption patterns were food, medication or healing, replacement for sugar and margarines and as tej with minimum quantity.

The significant factors were education level, income level, household size, availability, quality issues, price, and policy issues have positive and significance influences while price has negative and significant influences on the consumption of honey. On the other hand, sex and age of household head, market information, and distance to market did not have significant influence on honey consumption of households. In addition, household socio-economic characteristics, market characteristics, and policy issues influenced the choice of honey consumption among households.

The following points were recommended for further study:

Societal awareness creation to stimulate the vitality of honey consumption.

1. Devise mechanism of honey traceability to address quality issues.

2. Promote and empower beekeepers in the region and increase availability of honey.

3. Managing and control the regular increase in price.

4. Develop honey consumption record practices.

5. Coordinated governmental and nongovernmental stakeholder's engagement and clear registration record in honey consumption pattern in due to time.

\section{References}

[1] Batt, P. and Liu, A. (2012). Consumer behavior towards honey products. In Western Australia. British Food Journal 114 (2): 285-297 pp.
[2] Famuyide, O., Adebayo, O., Owese, T., Azeez, F., Arabomen, O., Olugbire, O. \& Ojo, D., (2014). Economic Contributions of Honey Production as Livelihood Strategy Means in Oyo State in International Journal of Science and Technology 3 (1): 7-11 pp.

[3] Adgaba N. and Negera E. (2007). Study on Means of Retarding the Unwanted Granulation of Table Honey. Holleta Bee Research Center, Progress Report, Holleta, Ethiopia.

[4] FAO (Food and Agriculture Organization), 2005. Statistical Data Base - Livestock. http://faostat.fao.org/default.aspx.

[5] CSA (Central Statistical Agency), (2013). Agricultural Sample Survey on Livestock and Livestock Characteristics: Vol. (2), No. 570, April, 2013, Addis Ababa.

[6] Beyene, T. and David P. (2007). Ensuring Small Scale Producers in Ethiopia to Achieve Sustainable and Fair Access to Honey Markets. IDE and ESAT. Addis Ababa, Ethiopia.

[7] Werkneh A. (2007). Determinant of Adoption of Improved Box hive in Atsbi-wemberta District of Eastern Zone Tigray Region Ethiopia. Haramaya University, Ethiopia.

[8] Assefa, A. (2009). Market Chain Analysis of Honey Production: in Atsbi-wemberta district, Eastern Zone of Tigray National regional State. Haramaya University-Ethiopia.

[9] Mekonen T., Gidey Y., Tewelde H., Solomon A., 2011. Prospects of Beekeeping in the Northern Ethiopian Highlands: Scientific Research and Essays. Mekelle, Ethiopia Vol. 6 (29): 6039-6043.

[10] Belets, G., and Berhanu G. (2014). Adoption of Improved Box Hive Technology: Analysis of Smallholder Farmers in Northern Ethiopia. Journal of Agricultural Economics and Extension, Vol. 2 (2): 77-82.

[11] Mugenda M. \& Mugenda A. (2003). Research Methods; Quantitative and Qualitative Approaches. Act Press Nairobi.

[12] Šedík, P., Pocol C., Horská, E. and Fiore, M. (2019), Honey: food or medicine? A comparative study between Slovakia and Romania, British Food Journal, Vol. 121 No. 6, pp. 12811297. https://doi.org/10.1108/BFJ-12-2018-0813.

[13] Gujarati, D. (2004). Basic Econometrics. $4^{\text {th }}$ edition. MacGraw-Hill International Edition.

[14] Raymond, O. (2017). Assessment of factors influencing the consumption of honey in Mwanza City, Tanzania. Sokoine University of Agriculture. Morogoro, Tanzania.

[15] Ismaiel, S., Al Kahtani, S., Nuru Adgaba, N., Al-Ghamdi, A. A., and Abdu Zulail, A. (2014). Factors that Affect Consumption Patterns and Market Demands for Honey in the Kingdom of Saudi Arabia. In Journal of Food and Nutrition Sciences. 5: 1725-1737 pp. 